\title{
A semi-empirical model to predict excess pore pressure generation in partially saturated sand
}

\author{
Sayedmasoud Mousavi ${ }^{1}$, and Majid Ghayoomi ${ }^{2, *}$ \\ ${ }^{1}$ Graduate Student, University of New Hampshire, Dept. of Civil and Environmental Engineering, Durham, NH, USA \\ ${ }^{2}$ Associate Professor, University of New Hampshire, Dept. of Civil and Environmental Engineering, Durham, NH, USA
}

\begin{abstract}
Past studies revealed that excess pore pressure generation due to cyclic loading is highly governed by induced strains, volumetric deformation potential of soil, number of cycles, and bulk stiffness of pore fluid. It is well established that partial saturation can significantly reduce bulk stiffness of pore fluid and consequently excess pore pressure generation during seismic loading. On the basis of that, a number of researchers have investigated induced partial saturation as an effective soil improvement technique to increase the liquefaction resistance of fully saturated soils. This paper focuses on development of a semiempirical model to interpret the effects of partial saturation on the excess pore pressure generation in sands. In this regard, an existing strain based excess pore pressure ratio $\left(r_{u}\right)$ prediction model originally developed for fully saturated soils was modified to incorporate the effect of partial saturation on the excess pore pressure generation. The literature data as well as data from a series of strain-controlled direct simple shear test were used to evaluate the reliability of the proposed equation in predicting the excess pore pressure ratio in partial saturation condition.
\end{abstract}

\section{Introduction}

Seismic loadings such as earthquakes induce cyclic shear strains resulting in rearrangement and densification of soils to a more stable condition. Because the pore space of saturated soils is filled with a relatively incompressible fluid like water, the pore fluid resists against densification under an undrained condition, which leads to pore pressure build-up. This generation of pore pressure is the main mechanism in seismically induced liquefaction. In addition, pore pressure generation can significantly affect the overall seismic response including wave propagation (i.e. site response), seismic settlement, and stability; even if it does not lead to liquefaction [1-2].

The pore pressure generation mechanisms during dynamic loadings and factors governing its amplitude have been studied for many years [3-7]. Previous research indicated that the excess pore pressure generation $(\Delta u)$ is mainly governed by induced volumetric strains and soil and fluid stiffness characteristics, and can be estimated using the following equation $[5,7,8]$ :

$$
\Delta u=\frac{\Delta \varepsilon_{v d}}{\frac{1}{E_{r}}+\frac{n_{p}}{K_{f}}}
$$

where $\Delta u$ is the excess pore pressure, $\Delta \varepsilon_{v d}$ is soil volumetric strains, $E_{r}$ is rebound modulus of soil skeleton, $n_{p}$ is porosity of soil, and $K_{f}$ is the bulk stiffness of pore fluid. The induced volumetric strains in soil is highly affected by induced shear strains, soil type and density, and number of loading cycles, among other factors [9].

The bulk stiffness of pore fluid is very sensitive to the existence of gas and is related to soil's degree of saturation, $S_{r}$ as follows:

$$
K_{f}=\frac{1}{\frac{S_{r}}{K_{w}}+\frac{1-S_{r}}{K_{g}}}
$$

where $K_{w}$ is the bulk stiffness of water $\left(K_{w} \approx 2.2 \mathrm{GPa}\right)$ and $K_{g}$ is the bulk stiffness of gas $\left(K_{g} \approx 142 \mathrm{kPa}\right)$. Figure 1 presents the evolution of fluid bulk stiffness with degree of saturation. Only a small reduction in degree of saturation of a fully saturated soil significantly reduces the fluid bulk stiffness and consequently the excess pore pressure generation according to Fig. 1 and Eq. 1 . Experimental studies have also confirmed the significant effect of desaturation on pore pressure generation and liquefaction resistance of soils [10-14]. These facts strongly suggest that induced partial saturation can show promise as an effective measure for liquefaction mitigation.

In recent years, quite extensive research has been conducted on development of effective techniques to induce partial saturation in soils and understanding their effect on their liquefaction resistance. However, development of a framework for estimation of excess 
pore pressure generation in partially saturated soil has received little attention. This paper focuses on development of a semi-empirical model to interpret the effects of partial saturation on the excess pore pressure generation in sands. In this regard, an existing strain based excess pore pressure generation prediction model originally developed for fully saturated soils was modified to incorporate the effect of partial saturation on the excess pore pressure generation. The literature data as well as data from a series of strain-controlled direct simple shear test were used to evaluate the reliability of the proposed equation in predicting the excess pore pressure ratio in partial saturation condition.

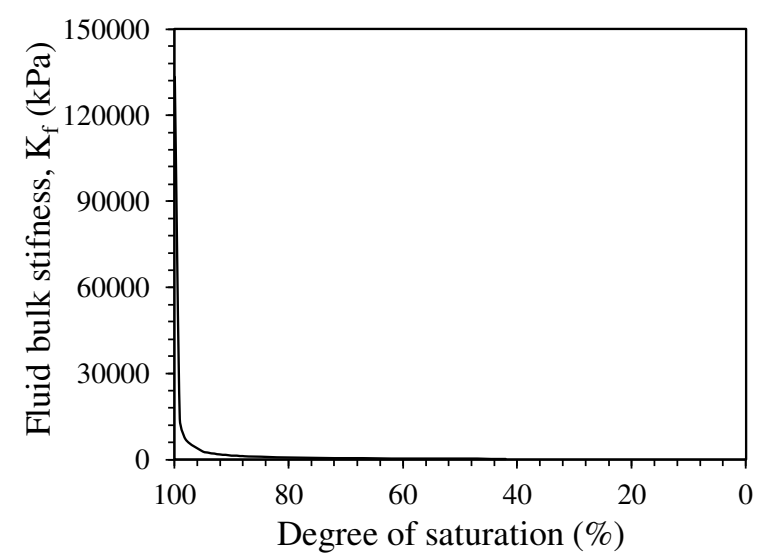

Fig. 1. Effect of soil saturation on the bulk stiffness of pore fluid.

\section{Excess pore pressure models}

A number of methodologies have been developed to quantitatively estimate the excess pore pressure generation in fully saturated soils. The methods can be generally categorized as (1) stress-based [4] and (2) strain-based [3] models. Theoretical and experimental studies indicate that the generation of excess pore pressure is mainly controlled by induced volumetric strain (Eq. 1), and that induced volumetric strain is mainly governed by the level of induced shear strains [3, 9]. Thus, strain-based models provide a more fundamental basis for estimation of pore pressure generation in soils.

Dobry [15] compiled data from seven series of undrained cyclic strain-controlled direct simple shear, cyclic triaxial, and cyclic torsional shear tests on undisturbed as well as remolded samples at varying effective confining stresses from 25 to $200 \mathrm{kPa}$ and relative densities from $20-80 \%$. Results suggested a clear trend between induced shear strain and excess pore pressure generation in sands [15]. The results also indicated the existence of a strain level below which no significant pore pressure develops. This stain level is referred to as threshold shear strain, $\gamma_{t v p}$ and is around 0.01 to $0.02 \%$ for most sands [3]. On the basis of the laboratory observations and Martin et al. [5] theoretical model, Dobry [15] proposed a strain-based methodology to predict pore pressure generation in fully saturated sands, as follows:

$$
r_{u, N}=\frac{p \times f \times N \times F \times\left(\gamma-\gamma_{t v p}\right)^{s}}{1+f \times N \times F \times\left(\gamma-\gamma_{t v p}\right)^{s}}
$$

where $r_{u, N}$ is the excess pore pressure ratio at Nth cycle of loading, defined as the ratio of the excess pore pressure to vertical effective stress, $\sigma_{\mathrm{v}}^{\prime}\left(\Delta u / \sigma_{\mathrm{v}}^{\prime}\right) . \gamma$ is the induced shear strain. $f$ is dimensionality factor and can be assumed as 1 or 2 , depending on whether pore pressures is induced by one-or two-directional shaking. $F, p$, and $s$ are fitting parameters which depend on volumetric deformation potential of soils and can be obtained by laboratory data-based fitting attempts. The model's fitting parameters can also be derived by empirical equations. The parameter $F$ is reversely proportional to the shear wave velocity of soil and takes the following functional form [16]:

$$
F=3810 \times V_{s}^{-1.55}
$$

where $V s$ is the shear wave velocity of soils in fully saturated condition. The fitting parameter $\mathrm{s}$ is proportional to soil's fine content (FC) and can be presented as follows [16]:

$$
s=(F C+1)^{0.1252}
$$

Laboratory data on different types and relative densities of sands indicated that values for parameter $p$ varies between $\pm 7.1 \%$ of 1 [17].

\section{Proposed model}

Although Eq. (3) has shown to be capable of estimating $r_{u}$ in fully saturated soils, it does not directly consider the effect of degree of saturation on excess pore pressure generation; even though this was considered in the theoretical formulation by Martin et al. [5]. In their theoretical formulation (Eq. 1), Martin et al. [5] showed that excess pore pressure generation is proportional to bulk stiffness of pore fluid. As discussed earlier, the bulk stiffness of pore fluid is highly governed by soil degree of saturation (Eq. 2 and Fig. 1). To capture the effect of partial saturation on the excess pore pressure generation, Eq. 3 was modified by implementing the effect of fluid bulk stiffness in partially saturated condition into Eq. 3 . In this regard, a semi-empirical equation for prediction of $r_{u}$ in partially saturated condition can be obtained by implementing the ratio of pore fluid bulk stiffness in partially saturated condition to fully saturated condition into Eq. 3 as follows:

$$
r_{u, N}=\frac{\left(\frac{K_{f}}{K_{f_{0}}}\right) \times p \times f \times N \times F \times\left(\gamma-\gamma_{t v p}\right)^{s}}{1+\left(\frac{K_{f}}{K_{f_{0}}}\right) \times f \times N \times F \times\left(\gamma-\gamma_{t v p}\right)^{s}}
$$

where $K_{f, 0}$ is the initial pore fluid bulk stiffness at which the fitting parameters are obtained (i.e. fully saturated 
condition) and $K_{f}$ is the bulk stiffness of pore fluid in partially saturated condition, which can be calculated from Eq. 2.

The methodology to obtain these parameters within the proposed equation's relies on undrained staincontrolled test on saturated samples or empirical correlations discussed in previous section. Overall, the parameters required to estimate the evolution of $r_{u}$ during constant-strain cyclic loading include the fitting parameters $(p, F, s)$ and the threshold shear strain value obtained from cyclic tests on saturated samples at various shear strain amplitude as well as the $K_{f}$ and $K_{f 0}$ calculated from Eq. 2. Since the direct measurement of degree of saturation in a nearly saturated sample is difficult, the initial bulk stiffness of pore fluid can be indirectly calculated from B-value measurements.

\section{Model validation}

In order to examine the applicability of the proposed equation for prediction of $r_{u}$ in a partially saturated state, the model was first calibrated by strain-controlled test results on saturated sands available in literature as well as data from this study and then estimated values from the proposed model was compared with the data obtained from tests on induced partially saturated soils.

\subsection{Literature data}

The experimental measurements by Eseller-Bayat et al. [12] were identified from literature for which $r_{u}$ data on both fully saturated and induced partially saturated soil were available. They utilized a cyclic simple shear liquefaction box to perform a series of strain-controlled simple shear tests on saturated and induced partially saturated sands [12]. The induced partial saturation was achieved by wet pluviation of sodium perborate monohydrate mixed with Ottawa sand where the reaction of the sodium perborate with pore water reduced degree of saturation by releasing oxygen bubbles. Sand specimens with different degrees of saturation were subjected to constant cyclic strains at various levels.

Fig. 2 represents $r_{u}$ data obtained from cyclic tests on fully saturated sand samples at relative density $\mathrm{D}_{\mathrm{r}}=30$ $40 \%$, average effective stress, $\sigma_{v}^{\prime}=2.5 \mathrm{kPa}$, and 2 and 10 number of cycles, $N$ [12]. Regardless of magnitude of induced shear strain, the data shows higher values of $r_{u}$ at 10 cycles of loading than $\mathrm{N}=2$. The excess pore pressure data shows a clear trend with shear strain level, increasing as the shear strain increases. Although the excess pore pressure data at shear strains lower than $0.005 \%$ was not reported, threshold shear strain is expected to be lower than $0.005 \%$ and was assumed to be $0.002 \%$. This value appears to be considerably lower than the typical range $(0.01 \%$ to $0.02 \%)$ for sands reported in previous studies. This may be due to very low effective stress at which the specimens were subjected to cyclic loadings.

The parameters in Eq. 6 were calibrated using the empirical methodology described in section 2. Since the cyclic tests were conducted in one dimension, $f=1$ was used in the model. Parameter $F$ was obtained using the shear wave measurements reported by Eseller-Bayat et al. [12]. The shear wave velocity of a fully saturated sample at the bottom of the sample $\left(\sigma_{v}^{\prime}=9.6 \mathrm{kPa}\right)$ was approximately $70 \mathrm{~m} / \mathrm{s}$. Since the shear wave velocity is proportional to soil's effective stress [16], its value varied from 0 at soil surface to $70 \mathrm{~m} / \mathrm{s}$ at the bottom of sample. Therefore, an average shear wave velocity of 35 $\mathrm{m} / \mathrm{s}$ was considered to obtain parameter $F$. For clean sand tested in Eseller-Bayat et al. [12], parameter $s=1$ was used in the model. Finally, a value of $p=1.07$ was used to fit Eq. 3 to the experimental measurements. Table 1 presents a summary of model parameters for prediction of $r_{u}$ in fully saturated sand. Using these parameters, the model was found to provide an acceptable prediction of $r_{u}$ data at different strain values and number of cycles (Fig. 2).

Table 1. A summary of model parameters.

\begin{tabular}{|c|c|c|c|c|}
\hline Parameter & $f$ & $p$ & $s$ & $F$ \\
\hline value & 1 & 1.07 & 1 & 16 \\
\hline
\end{tabular}

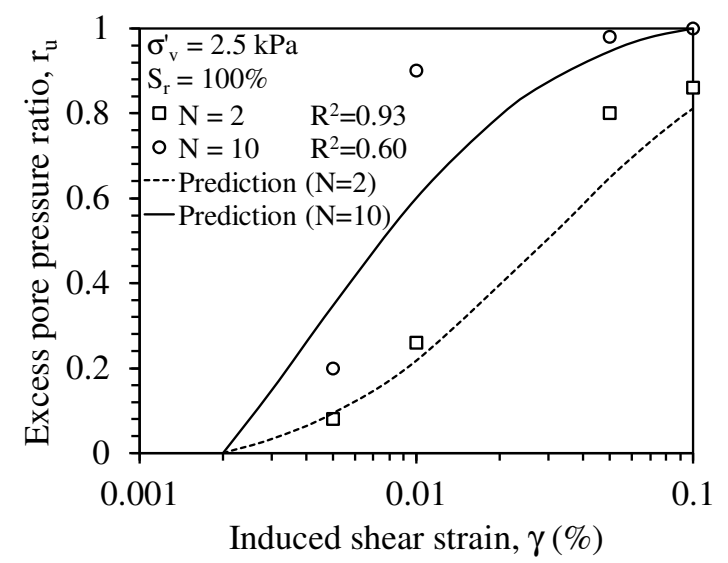

Fig. 2. Comparison of the predicted excess pore pressure ratio data of fully saturated samples with those measured experimentally by Eseller-Bayat et al. [12].

Fig. 3 presents $r_{u}$ data obtained from cyclic tests on sand samples at various degrees of saturation, $\mathrm{N}=2$ and 10 , and $\gamma=0.1 \%$. Regardless of number of cycles of loading, initial liquefaction did not occur in partially saturated samples. The $r_{u}$ versus degree of saturation curves showed a dramatic reduction in excess pore pressure ratio with reduction in degree of saturation up to around $72 \%$. The $r_{u}$ was less affected by lowering the $S_{r}$ from $72 \%$ to $60 \%$. This behaviour is very similar to trends observed in fluid bulk stiffness versus $S_{r}$ curves, which confirms the significant impact of $K_{f}$ on pore pressure response of soils.

In order to examine the suitability of the proposed model to predict excess pore pressure ratio in partially saturated condition, predicted $r_{\mathrm{u}}$ values using Eq. 6 were plotted along with the experimental measurements by Eseller-Bayat et al. [12] in Fig. 3. The fluid bulk stiffness at different saturation levels were estimated using Eq. 2. It is noteworthy that since the existence of 
dissolved gas can influence the fluid bulk stiffness of a saturated soil, $K_{f, 0}$ is not always equal to that of de-aired water. The initial pore fluid bulk stiffness must be calculated based on initial B-value of soil sample in saturated condition. Since the B-value measurements were not available, $K_{f, 0}=30 \mathrm{MPa}$ was assumed, in order to fit the model to the experimental data. This value suggests that the degree of saturation in saturated samples was approximately $99.5 \%$.

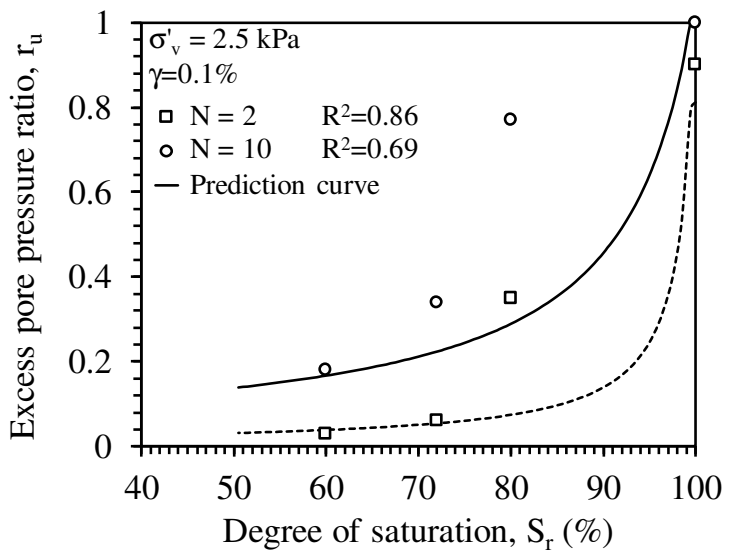

Fig. 3. Comparison of the predicted pore pressure ratio data of induced partially saturated sand with those measured experimentally by Eseller-Bayat et al. [12].

The model was found to provide a good prediction of excess pore pressure generation ratio reported by Eseller-Bayat et al. [12]. The model predicted a dramatic drop in the excess pore pressure ratio as the degree of saturation decreases which followed by a gradual decrease in $r_{u}$ with further reduction in the degree of saturation; a behavior which was found consistent with the experimental results as presented in Fig. 3. However, a considerable discrepancy was found between the model prediction and reported $r_{u}$ values at $S_{r}=80 \%$. Two reasons may explain the discrepancies observed between the model prediction and $r_{u}$ values : 1) very low effective stress at wich samples were tested; the effective stress varied from 0 to $9.6 \mathrm{kPa}$ and any shaking could result in large deformation of soil particles at soil surface level. 2) application of several cyclic test on one sample; previous experiments have revealed that re-shearing the specimens significantly influence their volumetric deformation and pore pressure response [17-18]. Thus, although reported data by Eseller-Bayat et al. [12] revealed the significance of induced partial saturation on pore pressure response, further laboratory data is required in order to examine the adequancy of the proposed model for excess pore pressure prediction.

\subsection{Experimental investigation}

To further examine the adequacy of the proposed model for prediction of $r_{u}$ in a partially saturated state, the model was fit to data points obtained from an experimental program using a Direct Simple Shear (DSS) test setup. The testing setup and procedures for this device were described in detail by Mousavi and Ghayoomi [19-20] and are briefly described here.

\subsubsection{Tested material and Experimental procedures}

The soil used in this study were reconstituted F-75 Ottawa sand samples. The sand was a fine silica sand classified as poorly graded sand (SP) according to Unified Soil Classification System (USCS). Table 2 describes a summary of physical and geoetechnical properties of the sand tested in this study.

Table 2. A summary of physical and geotechnical properties of the Ottawa sand.

\begin{tabular}{|c|c|}
\hline Property & value \\
\hline Coefficient of curvature, $\mathrm{C}_{\mathrm{c}}$ & 1.74 \\
\hline Coefficient of uniformity, $\mathrm{C}_{\mathrm{u}}$ & 1.08 \\
\hline $\mathrm{D}_{50}(\mathrm{~mm})$ & 0.19 \\
\hline $\mathrm{D}_{10}(\mathrm{~mm})$ & 0.12 \\
\hline Specific gravity, $\mathrm{G}_{\mathrm{s}}$ & 2.65 \\
\hline Void ratio limits, $e_{\min }, e_{\max }$ & $0.49,0.8$ \\
\hline
\end{tabular}

The DSS apparatus utilized in this study includes a Swedish Geotechnical Institute (SGI) configuration soil cell with a stack of Teflon coated aluminum rings. Dry pluviation method was employed in order to prepare cylindrical sand with identical relative density $\mathrm{Dr} \approx 55 \%$. Carbon dioxide $\left(\mathrm{CO}_{2}\right)$ permeation and backpressure methods were used to ensure full saturation of samples. Pore pressure parameter (B-value) was recorded at the end of saturation process and specimens were consolidated at $50 \mathrm{kPa}$ vertical effective stress.

Induced partial saturation was achieved by using microbial induced partial saturation (MIPS) via denitrification. This process utilizes microbial anaerobic respiration to reduce nitrate to nitrogen gas. The generated nitrogen gas then exsolve in pore fluid and form tiny gas bubbles within the pore space. Mousavi and Ghayoomi [21] showed that the degree of saturation in this method can be adjusted by adjusting the initial concentration of nitrate. In order to desaturate samples using MIPS process, saturated soil samples were flushed by a solution medium containing a mixture of Paracoccus denitrificans (ATCC 17741) bacteria and a nutrient medium that had mineral salts and ethanol and nitrate at different concentrations. The solution volume was at least three times volume of the soil samples' pore volume. The degree of saturation at the end of this process was calculated by measuring the volume of expelled water from sample as a result of gas formation in the soil pores. Details of MIPS process using denitrification process are elaborated in Mousavi and Ghayoomi [21].

Strain-controlled tests were performed at $0.1 \mathrm{~Hz}$ frequency for 20 cycles of loading at a constant shear level. All tests were conducted in an undrained condition 
and the excess pore pressure ratio were calculated by recording the pore pressure during cyclic loading.

\subsubsection{Experimental results}

Experimental results from undrained strain-controlled DSS tests are presented in terms of excess pore pressure ratio with induced shear strain. Fig. 4 shows the excess pore pressure ratio of Ottawa sand samples subjected to various shear strain levels. This figure shows a clear dependency of the magnitude of excess pore pressure on number of cycles and induced shear strain level. The results also indicate that the threshold shear strain falls between 0.005 and $0.025 \%$. The magnitude of threshold shear strain was assumed to be $0.012 \%$ based on the observed trends in $r_{u}$ versus $\gamma$ curves. This value agrees well with the reported ranges for clean sands.

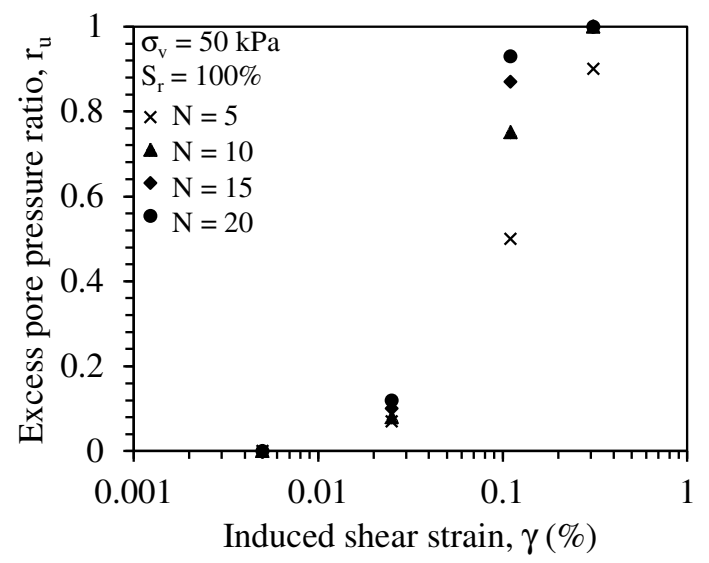

Fig. 4. Excess pore pressure ratio of fully saturated sand samples versus induced shear strain.

Fig. 5 illustrates the excess pore pressure generation ratio of MIPS treated samples at different degrees of saturation and $\mathrm{N}=10$ and $\mathrm{N}=20$. Regardless of induced shear strain level, the $r_{u}-S_{r}$ curves showed a dramatic drop in $r_{u}$ values when the degree of saturation decreased to $90 \%$. The excess pore pressure magnitude was less influenced by desaturation for saturation levels lower than $90 \%$. This behavior is very similar to theoretical trends of fluid bulk stiffness observed in Fig. 1.

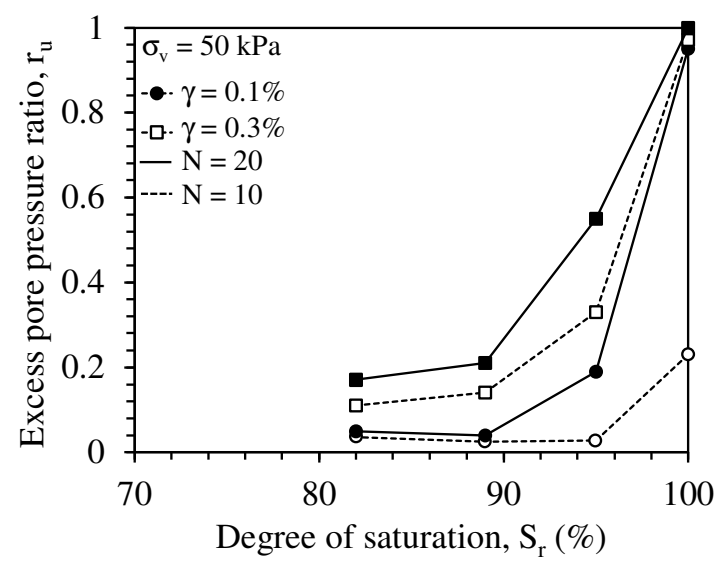

Fig. 5. Excess pore pressure ratio versus sample's degree of saturation.

\subsubsection{Model calibration and verification}

The proposed model parameters were obtained by fitting the predicted values of Eq 6. to the experimental $r_{u}$ data points of fully saturated tests using a least square fitting method. Table 3 presents a summary of the fitting parameters' values. Using these parameters, the model yielded a very well prediction of the experimental data obtained in this study.

Table 3. A summary of model parameters.

\begin{tabular}{|c|c|c|c|c|}
\hline Parameter & $f$ & $p$ & $s$ & $F$ \\
\hline value & 1 & 1.07 & 1 & 16 \\
\hline
\end{tabular}

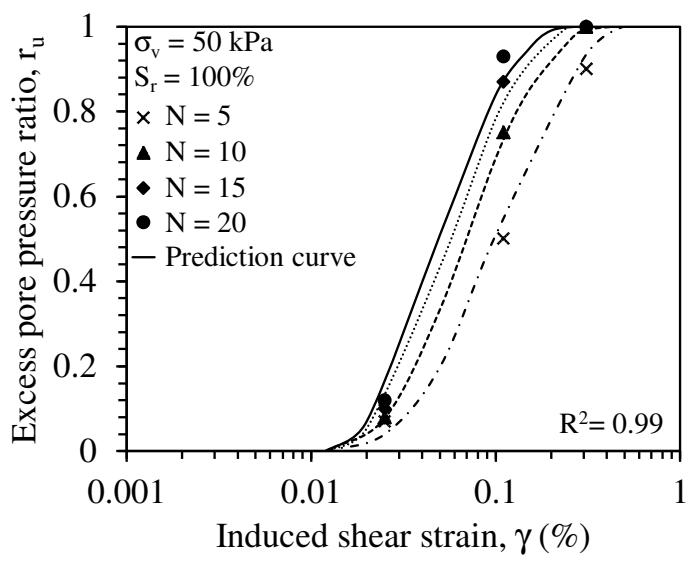

Fig. 6. Comparison of model prediction with the experimental excess pore pressure ratio data for fully saturated tests.

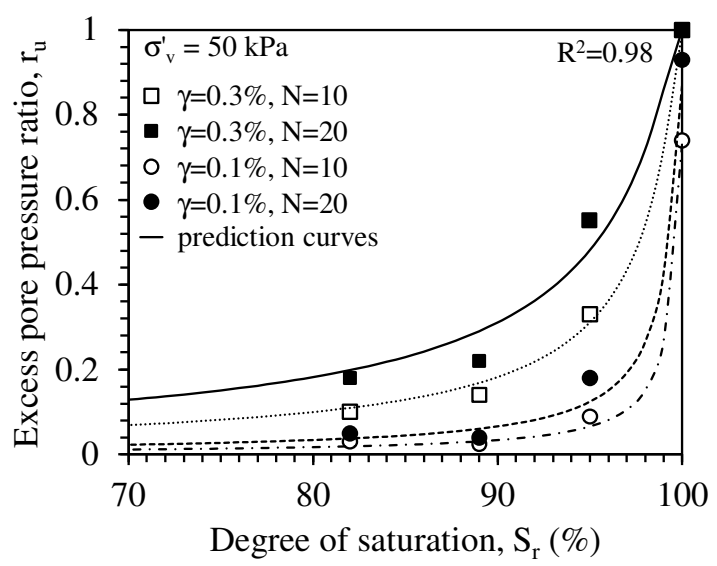

Fig. 7. Comparison of model prediction with the experimental excess pore pressure ratio for partially saturated specimens.

The fitting parameters obtained for fully saturated tests were used to examine the Eq. 6 suitability to predict the experimental $r_{u}$ data for samples in a partially saturated condition (Fig. 7). The model successfully captured the dramatic drop in the excess pore pressure ratio of MIPS treated samples with reduction in degree of saturation from full saturation to $S_{r} \approx 90 \%$. The model prediction showed a gradual reduction in excess pore pressure ration with degree of saturation reduction to values lower than 90\%; a behavior which was found consistent with the experimental results as presented in 
Fig. 7. The model's adequacy to predict the experimental $r_{u}$ data was also evaluated by calculating the coefficient of determination $\left(\mathrm{R}^{2}\right)$. Results indicated $\mathrm{R}^{2}$ value of approximately 0.98 for the data points which indicates very good consistency of the predicted $r_{u}$ values from the model with the experimental measurements.

\section{Conclusion}

The excess pore pressure generation in cyclically loaded partially saturated soils is a topic that has received little attention and deserves further investigation. A new semiempirical model was presented in this study to represent the impact of partial saturation on the excess pore pressure generation of partially saturated soils. In this regard, an existing strain-based model generally developed for fully saturated soils was modified to capture the impacts of fluid bulk stiffness reduction due to desaturation on the excess pore pressure response of soils subjected to cyclic loading. A methodology also was presented to calibrate the proposed model's parameters. The new model was found to fit well for the $r_{u}$ measurements reported in the literature as well as the experimental results in this study. The results presented in this study reflected considerable impacts of $S_{r}$ on the excess pore pressure generation of sands. However, further testing of partially saturated soils with different types and initial conditions (e.g. density and effective stress) is needed to assess the capability of the proposed model to characterize the pore pressure response of soils in partially saturated conditions.

\section{References}

1. K. Hazirbaba, E.M. Rathje, E. M. Pore pressure generation of silty sands due to induced cyclic shear strains. J. Geotech. Geoenviron. Eng., 135, 12, (2009)

2. M. Mirshekari, M. Ghayoomi. Effects of shaking intensity on seismic response of unsaturated sand layers. In Vol. 1 of Proc., 7th Int. Conf. on Unsaturated Soils, (2018)

3. R. Dobry, R. Ladd, F. Yokel, R. Chung, D. Powell. Prediction of pore water pressure build-up and liquefaction of sands during earthquakes by the cyclic strain method. NBS Building Science Series 138 (1982)

4. H.B. Seed, I.M. Idriss, F. Makidisi, N. Banerjee. The generation and dissipation of pore water pressures during soil liquefaction. Rep. No. EERC 75-26, Univ. of California, Berkeley, Calif. (1975).

5. G.R. Martin, W.D.L. Finn, Seed H.B. Fundamentals of liquefaction under cyclic loading. J. Geotech. Engrg. Div., 101, 5 (1975)

6. C.P. Polito, R.A. Green, and J. Lee. Pore pressure generation models for sands and silty soils subjected to cyclic loading. Journal of Geotechnical and Geoenvironmental Engineering 134, 10 (2008)
7. W.L. Finn, P.M. Byrne, G.R. Martin. Seismic response and liquefaction of sands. J. Geotech. Geoenviron. Eng. Dev. 102. (1976)

8. S. Mousavi, M. Ghayoomi. Liquefaction mitigation of sands with non-Plastic fines via microbial induced partial saturation. J. of Geotech. and Geoenvir. Eng.- Under review (2019)

9. P.M. Duku, J.P. Stewart, D.H. Whang, E. Yee. Volumetric strains of clean sands subject to cyclic loads. J. geotech. and geoenvir. Eng., 134, 8 (2008)

10. R.C. Chaney. Saturation effects on the cyclic strength of sands. In From Vol. I Earthquake Eng. Soil Dyn. -Proc. ASCE Geotech. Eng. Div. Spec. Conf., June (1978), Pasadena, California.

11. M. Okamura, K. Noguchi. Liquefaction resistances of unsaturated non-plastic silt. Soils and Found., 49, 2, (2009).

12. S. Mousavi, M. Ghayoomi. Dynamic shear modulus of microbial induced partially saturated sand. Proc. Int. Symp. Bio-mediated Bio-inspired Geotech., Atlanta, in press.

13. S. Mousavi, M. Ghayoomi. Liquefaction mitigation of silty sands via microbial induced partial saturation. In Geo-Congress 2019: Earthquake Engineering and Soil Dynamics. (2019)

14. E. Eseller-Bayat, M.K. Yegian, A. Alshawabkeh, S. Gokyer. Liquefaction response of partially saturated sands. I: Experimental results. J. Geotech. Geoenviron. Eng., 139, 6 (2013).

15. R. Dobry. Liquefaction of soils during earthquakes. Rep. No. CETS-EE-001, National Res. Council NRC, Committee on Earthquake Engineering, Washington, D.C. (1985)

16. Carlton, B. (2014). “An Improved Description of the Seismic Response of Sites with High Plasticity Soils, Organic Clays, and Deep Soft Soil Deposits." $\mathrm{PhD}$ Thesis. University of California, Berkeley.

17. Y.M.A Hashash. DEEPSOIL V3.5 1-D nonlinear and equivalent linear wave propagation analysis program for geotechnical seismic site response analysis of soil deposits. User Man. and Tut., (2006)

18. H.B. Seed, R.T. Wong, I.M. Idriss, K. Tokimatsu. Moduli and damping factors for dynamic analyses of cohesionless soils. J. Geotech. Eng., 112, 11 (1986).

19. H.B. Seed, K. Mori, and C.K. Chan. Influence of seismic history on liquefaction of sands. J. Geotech. Engrg. Div., 103 (1977)

20. E. Yee, P.M. Duku, J.P. Stewart. Cyclic volumetric strain behavior of sands with fines of low plasticity. Journal of Geotechnical and Geoenvironmental Engineering, 140, 4 (2013).

21. S. Mousavi, M. Ghayoomi, S.H. Jones. Compositional and Geo-Environmental Factors in Microbial Induced Partial Saturation. Environ. Geotech. (2019) 